\title{
Mandibular Condyle: Structure Properties and Growth Regulation
}

\author{
Chong Ren' and Yanqi Yang ${ }^{*}$ \\ 'Orthodontics, Faculty of Dentistry, The University of Hong Kong, Hong Kong SAR, China
}

\section{"CorResponding AUthoR:}

Yanqi Yang

Assistant Professor in Orthodontics Orthodontics, Faculty of Dentistry the University of Hong Kong

2/F, Prince Philip Dental Hospital

34 Hospital Road

Hong Kong SAR, China

Tel: $+852-28590252$

Fax: $+852-25593803$

E-mail: yangyanq@hku.hk

Received: 21 Jul 2014

Accepted: 26 Jul 2014

Published: $28 \mathrm{Jul} 2014$

(c) terms of the Creative Commons Attribution License, which permits unrestricted use and redistribution provided that the original author and sourceare credited.

Competing interests: The authors declare that no competing interests exist.

Access This Article

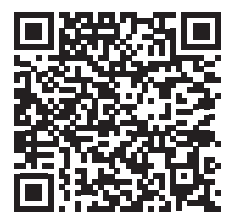

\section{INTRODUCTION}

Malocclusion is a developmental condition. In most instances, malocclusion and dentofacial deformity arise from variations in the normal development, and so it must be evaluated against a perspective of natural growth. For mandible, the deficiency or excess will lead to the skeletal problems three-dimensionally. Thus, it is important to understand the growth discipline and the regulatory mechanism.

The mandibular condylar cartilage, which covers the surface of the mandibular condyle at the temporomandibular joint (TMJ), has long been considered as a critical growth site. ${ }^{[1]}$ It is unique in terms of several morphological, physiological and functional properties different from the articular cartilage of the long bones. However, compared to the well-studied developmental process in the growth plate of long bone, less has been explored on the regulatory mechanism of the mandibular condyle growth.

\section{THE CHARACTERISTICS OF MANDIBULAR CONDYLAR CARTILAGE}

Mandibular condylar cartilage was previously thought to be in the same category as the growth plate. However, it was later found that the condylar cartilage also posesses properties of epiphyseal cartilage. ${ }^{[2]}$ As a hybrid of hyaline and fibrocartilage, it has been categorized as chondroid bone, a tissue intermediate between bone and cartilage. Therefore, it functions as a growth site rather than a growth center.

Another characterization of condylar cartilage is that it is secondary cartilage which forms after the fetal period and responds to the mechanical forces acting on it. It is different from the primary cartilage that stems from the primary cartilaginous skeleton of the organism. Since the growth of primary cartilage is subject to general factors, mechanical devices can alternate its direction but not the amount of growth. On the contrary, the growth of condylar cartilage, the secondary cartilage, is subject to not only general factors such as growth hormones but also local factors, thus may be modulated by appropriate mechanical devices in both direction and amount of growth. ${ }^{[3]}$ 


\section{THE HISTOLOGICAL STRUCTURE OF THE CONDYLAR ARTICULAR CARTILAGE}

The condylar articular cartilage can be histologically stratified into four layers: articular zone, proliferative zone, fibrocartilage zone, ossification zone. ${ }^{[4]}$

The outermost layer of condylar articular cartilage is the articular zone or fibrous layer. The articular zone consists of fibroblasts, which is surrounded by a dense and avascular layer of Type I collagen. It has been found that fibroblasts in the deeper area of the articular zone in rat's condylar articular cartilage show proliferative activity. ${ }^{[5]}$ The articular zone is thought to possess self-contained and self-replicating characteristics.

The proliferative zone locates beneath the articular zone. This layer involves in the formation of the condylar cartilage by contributing cells to the fibrocartilage layer below rather than the articular zone above. As maturing, the cells in this layer ceases proliferation, yet persist and may resume proliferative activity in case of certain circumstances. ${ }^{[5]}$

Deeper adjacent to the proliferative zone lies the fibrocartilage zone, consisting of maturing chondroblasts stemming from the progenitor cells from the proliferative zone. These chondroblasts generate an extracellular matrix which is composed of proteoglycans and type II collagen. As these cells progress towards hypertrophy, they finally get surrounded by mineralized cartilage matrix in the ossification zone. ${ }^{[5]}$

As the fibrocartilage develops, endochondral ossification takes place. This process involves mineralization of the cartilage, invasion of blood vessels, apoptosis of the chondrocytes, differentiation of osteoblasts and bone deposition on the mineralized cartilage matrix.

The development of condyle cartilage share some common traits with that of the epiphyseal cartilage in long bones, yet differs in its absence of chondrocytes in ordered columns, thus facilitating multidirectional growth in response to developmental changes in other components of the craniofacial complex. ${ }^{[5]}$

\section{ChONDROCYTE DIFFERENTIATION AND ENDOCHONDRAL OSSIFICATION}

Wild interests have been triggered on the regulatory mechanism and matrix nature of cellular differentiation and cartilage ossification during condylar growth. With the development of the skeletal genetics and molecular biology, it has been found that, like the ossification process in the long bone, several factors endogenously expressed in the condyles have demonstrated significant effects on endochondral ossification. ${ }^{[6-12]}$

The transcription factor, Sex-determining Region on the $Y$ chromosome (SRY)-related high-mobility group (HMG) Box 9 (Sox9) is recognized to play a pivotal role in chondrocyte differentiation. The role of Sox 9 in chondrogenesis is not recognized until it is discovered that mutations in Sox9 can lead to campomelic dysplasia (CD), a rare human genetic disease, characterized by the hypoplasia of most skeletal components generating from endochondral ossification. ${ }^{[13,14]}$ Sox9 plays a critical role in chondrogenesis in two aspects. On one hand, it is essential to the differentiation of mesenchymal cells into chondrocytes. It has been shown that, in mouse embryos, the Sox9 gene is expressed in all chondroprogenitor cells and at higher level in chondrocytes. ${ }^{[15]}$ It was also found that misexpression of Sox9 in dermomyotomal cells can result in the deviation of these cells from their normal development into the axial musculature and dermis towards the cartilage differentiation programme. ${ }^{[16]}$ On the other hand, Sox9 regulates condylar cartilage formation by modulating the expression of type II collagen, the most abundant structural collagen component of cartilage, and other elements of cartilage-specific extracellular matrix (collagens IX, XI, the large proteoglycan aggrecan, etc.). ${ }^{[17,18]}$

Chondrocytes mature after cartilage matrix has been formed. Secreted by hypertrophic chondrocytes, type $X$ collagen is recognized as a marker for endochondral ossification and bone replacement of the cartilage matrix based on a series of research findings. ${ }^{[19-23]}$ On one hand, it is detected that type $X$ collagen initially appears when chondrocytes mature throughout the hypertrophic zone, whereas it is missing from the prolif-

Cite as: Ren C, Yang Y. Mandibular Condyle: Structure Properties and Growth Regulation. J Oral Sci Health. 2014;1 (1):1-6. 
erative zone ${ }^{[20]}$ It is suggested that type $X$ collagen is a unique component of the matrix of the hypertrophic cartilage andan important factor for endochondral bone formation. ${ }^{[7,21]}$ On the other hand, the expression of the type $X$ collagen gene precedes the onset of endochondral ossification. ${ }^{[22]}$ In vitro studies show that its expression precedes mineral deposition by cultured chondrocytes. ${ }^{[23]}$ Furthermore, type $X$ collagen is easier to be resorbed in comparison with type II collagen, facilitating the replacement of the hypertrophic cartilage with bone. ${ }^{[20]}$ Therefore, in the study of mandibular condylar growth, the spatial-temporal expression of type $X$ collagen should be correlated with the amount of bone formation.

Although type $\mathrm{X}$ is the marker of the chondrocyte hypertrophy, it alone cannot explain the triggering of osteogenesis. Osteogenesis (bone formation) is closely associated with angiogenesis (blood vessels invasion). ${ }^{[24]}$ The invading blood vessels bring osteogenic progenitor mesenchymal cells into the mineralization front. These cells later differentiate into osteoblasts and engage in osteogenesis. Vascular endothelial growth factor (VEGF) is known to be a potent regulator of neovascularization. ${ }^{[25]}$ Both in vivo and in vitro studies have demonstrated that VEGF receptor 2 can co-localize with the factor in hypertrophic cartilage, suggesting that there may be an autocrine loop in chondrocytes as they mature and hypertrophy. Antibodies against VEGF or VEGF receptor 2 inhibit endothelial cell migration. ${ }^{[8]}$ This finding indicates that VEGF plays a critical role in neovascularization of hypertrophic cartilage through a paracrine release targeting at invading endothelial cells by chondrocytes. ${ }^{[8]}$ When VEGF was inactivated by a soluble receptor chimeric protein systematically administered in mice, blood vessel invasion was almost completely suppressed. Meanwhile, trabecular bone formation is hampered accompanied by expansion of hypertrophic chondrocyte zone. ${ }^{[26]}$ Therefore, it is suggested that VEGF may also play an important role in regulating endochondral ossification in condyles by controlling neovascularization.

Osteoblasts, which carry out the function of osteogenesis, differentiate from progenitor mesenchymal cells brought by invading blood vessels. It has been disclosed that Core binding factor alpha 1 (Cbfa1) serves as a significant regulator of both osteoblast differentiation and bone matrix deposition..$^{[9,27-29]}$ It is targeted to the promoters of several bone proteins, including osteocalcin, alkaline phosphatase, bone sialoprotein and type I collagen. ${ }^{[28]}$ Besides, Cbfa1 is an indispensable regulator in chondrocyte maturation and hypertrophy during endochondral ossification. Cbfa1 is also responsible for the expression of VEGF and angiogenesis. Overall, Cbfa1 couples the process of chondrocytes maturation, bone matrix mineralization as well as osetoblasts differentiation during endochondral ossification.

Above all, the process of endochondral ossification involves a series of events which take place at a constantly moving interface between cartilage, invading blood vessels and bone with the coordination of many regulatory factors.

\section{REGULATION OF MANDIBULAR CONDYLAR GROWTH}

Since the condylar cartilage is different from the growth plate of long bone, researches on the regulatory mechanism of mandibular condylar growth are undoubtedly essential.Besides the condyle, the remodeling of glenoid fossa also plays an important role in the growth of mandible. Chondroid bone in the glenoid fossa possesses unique morphological and structural properties which intermediate between those of cartilage and bone. ${ }^{[30]}$ The cells in the chondroid bone may have the characteristics of osteocytes, rather than osteoblasts. They may differentiate from the hypertrophic chondrocytes that are derived from the adjacent secondary cartilage.

On this background, a series of researches have been carried out on the regulation mechanism of mandibular condylar growth and osteogenesis in the glenoid fossa. ${ }^{[19,31-38]}$ t has been found that a sequence of tran sitory events is engaged in condylar growth which is uniquely defined by endogenous factors synthesized by cells in the condyle. Sox 9 which is expressed by chondroprogenitor cells and chondrocytes regulates

Cite as: Ren C, Yang Y. Mandibular Condyle: Structure Properties and Growth Regulation. J Oral Sci Health. 2014;1 (1):1-6. 
chondrocyte differentiation and cartilage matrix formation. After the maturation of chondrocytes, Type $X$ is generated uniquely by hypertrophic chondrocytes prior to the onset of endochondral ossification. During endochondral ossification, hypertrophic chondrocytes secrete VEGF, whose level peak before the maximum bone formation. Localized in the osteoblasts and chondrocytes, Cbfa1 couples the process of chondrocytes maturation, bone matrix deposition, as well as osteoblasts differentiation. Thus, a complex and detailed evolving model of mandibular condyle has been presented with the participation of various key molecular factors. It is claimed that mandibular condylar growth can be modulated by bite-jumping appliances which bring mandibular position forward through stimulating the expression of Sox9, type II collagen, type $X$ collagen, VEGF, Parathyroid hormone-related protein (PTHrP) and Indian hedgehog (Ihh). ${ }^{[32,34-37,39,40]}$ These findings not only provide information for the effect of functional appliances at molecular level but also inspire further research on the regulation mechanism of mandibular condyle growth.

\section{References}

1. Sicher H. Growth of the mandible. Am J Orthod. 1947;33(1):30-35.

2. Salo LA, Hoyland J, Ayad S, et al. The expression of types $X$ and VI collagen and fibrillin in rat mandibular condylar cartilage. Response to mastication forces. Acta Odontol Scand. 1996;54(5):295-302.

3. Petrovic A, Stutzmann J. Growth hormone: mode of action on different varieties of cartilage. Pathol Biol (Paris). 1980;28(1):43-58.

4. De Bont LG, Liem RS, Boering G. Ultrastructure of the articular cartilage of the mandibuar condyle: aging and degeneration. Oral Surg Oral Med Oral Pathol. 1985;60:631-641.

5. Ten Cate AR. Temporomandibular Joint. Oral Histology: Development, Structure, and Function. 5th edition. St. Louis, Missouri: Mosby, 1998.

6. Lefebvre V, Huang W, Harley VR, et al. SOX9 is a potent activator of the chondrocyte-specific enhancer of the pro alpha1(II) collagen gene. Mol Cell Biol. 1997;17(4):2336-2346.

7. Olsen B, Reginato A, Wang W. Bone development. Annu Rev Cell Dev Biol. 2000;16:191-200.

8. Carlevaro MF, Cermelli S, Cancedda R, et al. Vascular endothelial growth factor (VEGF) in cartilage neovascularization and chondrocyte differentiation: auto-paracrine role during endochondral bone formation. J Cell Sci. 2000;113:59-69.

9. Otto F, Thornell AP, Crompton T, et al. CBFA1, a candidate gene for the cleidocranial dysplasia syndrome, is essential for osteoblast formation and bone development. Cell. 1997;89(5):765-771.

10. Huang W, Chung $U$, Kronenberg HM, et al. The chondrogenic transcription factor Sox9 is a target of signaling by the parathyroid hormone-related peptide in the growth plate of endochondral bones. Proc Natl Acad Sci U S A. 2001;98(1):160-165.

11. Karp SJ, Schipani E, St-Jacques B, et al. Indian Hedgehog coordinates endochondral bone growth and morphogenesis via parathyroid hormone related-protein-dependent and -independent pathways. Development. 2000;127(3):543-548.

12. Hamada T, Suda N, Kuroda T. Immunohistochemical localisation of fibroblast growth factor receptors in the ret mandibular condylar cartilage and tibial cartilage. J Bone Miner Metab. 1999;17(4):274-282.

13. Foster JW, Dominguez-Steglich MA, Guioli S, et al. Campomelic dysplasia and autosomal sex reversal caused by mutations in an SRY-related gene. Nature. 1994;372(6506):525-530.

14. Wagner T, Wirth J, Meyer J, et al. Autosomal sex reversal and campomelic dysplasia are caused by

Cite as: Ren C, Yang Y. Mandibular Condyle: Structure Properties and Growth Regulation. J Oral Sci Health. 2014;1 (1):1-6. 
mutations in and around the SRY-related gene SOX9. Cell. 1994;79(6):1111-1120.

15. De Crombrugghe B, Lefebvre V, Behringer RR, et al. Transcriptional mechanisms of chondrocyte differentiation. Matrix Biol. 2000;19(5):389-394.

16. Healy C, Uwanogho D, Sharpe PT. Regulation and role of Sox9 in cartilage formation. Dev Dyn. 1999;215(1):69-78.

17. Bi W, Deng JM, Zhang Z, et al. Sox9 is required for cartilage formation. Nat Genet. 1999;22(1):85-89.

18. Lefebvre V, De Crombrugghe B. Toward understanding Sox 9 function in chondrocyte differentiation. Matrix Biol.1998;16(9):529-540.

19. Rabie ABM, Shen G, Hagg U, et al. Type $X$ collagen-a marker for endochondral ossification of the mandibular condyle. Quintessence Year Book. 2000;16:50-58.

20. Poole AR and Pidoux I. Immunoelectron microscopic studies of type $X$ collagen in endochondral ossification. J Cell Biol. 1989;109(5):2547-2554.

21. Kwan KM, Pang MK, Zhou S, et al. Abnormal compartmentalization of cartilage matrix components in mice lacking collagen X: implications for function. J Cell Biol. 1997;136(2):459-471.

22. Kong RYC, Kwan KM, Lau ET, et al. Intron-exon structure, alternative use of promoter and expression of the mouse collagen X gene, Col10a-1. Eur. J. Biochem. 1993;213(1):99-111.

23. Kirsch T, Swoboda B, Von der Mark K. Ascorbate independent differentiation of human chondrocytes in vitro: simultaneous expression of types $\mathrm{I}$ and $\mathrm{X}$ collagen and matrix mineralization. Differentiation. 1992;52(1):89-100.

24. Yang $Y Q$, Tan $Y Y$, Wong $R$, et al. The role of vascular endothelial growth factor in ossification. Int $J$ Oral Sci. 2012;4(2):64-68.

25. Tan YY, Yang Y, Chai L, et al. Effects of Vascular Endothelial Growth Factor (VEGF) on MC3T3-E1. Orthod Craniofac Res. 2010;13(4):223-228.

26. Gerber HP, Vu TH, Ryan AM, et al. VEGF couples hypertrophic cartilage remodeling, ossification and angiogenesis during endochondral bone formation. Nat Med. 1999;5(6):623-628.

27. Komori T, Yagi H, Nomura S, et al. Targeted disruption of Cbfa1 results in a complete lack of bone formation owing to maturational arrest of osteoblasts. Cell. 1997;89(5):755-764.

28. Ducy P, Zhang R, Geoffroy V, et al. Osf2/Cbfa1: a transcriptional activator of osteoblast differentiation. Cell. 1997;89(5):747-754.

29. Yang Y, Yang YQ, Li XT, et al. Functional analysis of core binding factor a1 and its relationship with related genes expressed by human periodontal ligament cells exposed to mechanical stress. Eur $\mathrm{J}$ Orthod 2010;32(6):698-705.

30. Beresford WA. Chondroid bone, secondary cartilage \& metaplasia. Baltimore, Maryland: Urban \& Schwarzenberg, 1981.

31. Rabie ABM, Wong L, Tsai M. Replicating mesenchymal cells in the condyle and the glenoid fossa during mandibular forward positioning. Am J Orthod Dentofacial Orthop. 2003;123(1):49-57.

32. Rabie ABM, Tang $\mathrm{GH}$, Xiong $\mathrm{H}$, et al. PTHrP regulates chondrocyte maturation in condylar cartilage. J Dent Res. 2003;82(8):627-631.

33. Rabie ABM, Tang GH, Hagg U. Cbfa1 couples chondrocytes maturation and endochondral ossification

Cite as: Ren C, Yang Y. Mandibular Condyle: Structure Properties and Growth Regulation. J Oral Sci Health. 2014;1 (1):1-6. 
in rat mandibular condylar cartilage. Arch Oral Biol. 2004;49(2):109-118.

34. Rabie ABM, Shum L, Chayanupatkul A. VEGF and bone formation in the glenoid fossa during forward mandibular positioning. Am J Orthod Dentofacial Orthop. 2002;122(2):202-209.

35. Rabie ABM, She TT, Harley VR. Forward mandibular positioning up-regulates SOX9 and type II collagen expression in the glenoid fossa. J Dent Res. 2003;82(9):725-730.

36. Rabie ABM, She TT, Hagg U. Functional appliance therapy accelerates and enhances condylar growth. Am J Orthod Dentofacial Orthop. 2003;123(9):40-48.

37. Rabie ABM, Leung FY, Chayanupatkul A, et al. The correlation between neovascularization and bone formation in the condyle during forward mandibular positioning. Angle Orthod. 2002;72(5):431-438.

38. Rabie ABM and Hagg U. Factors regulating mandibular condylar growth. Am J Orthod Dentofac Orthop. 2002;122(4):401-409.

39. Shen G, Rabie ABM, Hagg U, et al. Expression of type $X$ collagen in condylar cartilage during mandibular protrusion. Hua Xi Kou Qiang Yi Xue Za Zhi. 2000;18(2):78-80,84.

40. Tang GH, Rabie ABM, Hagg U. Indian hedgehog: a mechanotransduction mediator in condylar cartilage. J Dent Res. 2004;83(5):434-438.

Cite as: Ren C, Yang Y. Mandibular Condyle: Structure Properties and Growth Regulation. J Oral Sci Health. 2014;1 (1):1-6. 